\title{
The Application of Electrochemical Impedance in the Environmentally Friendly Scale and Corrosion Inhibitor Polyepoxysuccinic ACID
}

\author{
B.R. Zhang \\ College of Environmental Science \& Engineering \\ State Key Laboratory of Pollution Control and Resource \\ Reuse \\ Tonji University \\ Shanghai, 200092, PR China \\ Key Laboratory of Yangtze River Water Environment Minis- \\ try of Education \\ College of Environmental Science and Engineering \\ Tongji University \\ 1239 Siping Road, Shanghai 200092, PR China
}

\author{
H.Y. Tian \\ College of Environmental Science \& Engineering \\ State Key Laboratory of Pollution Control and Resource \\ Reuse \\ Tonji University \\ Shanghai, 200092, PR China
}

F.T. Li

College of Environmental Science \& Engineering State Key Laboratory of Pollution Control and Resource Reuse

Tonji University

Shanghai, 200092, PR China

\begin{abstract}
Polyepoxysuccinic acid (PESA) is a new, nonphosphorous, biodegradable, environmentally friendly scale and corrosion inhibitor implemented in industrial water treatment. The corrosion and scale inhibition properties of PESA were investigated in the test water by using static beaker test, weightloss method, polarization curves and electrochemical impedance spectroscopy (EIS). It is found that, PESA has better scale inhibition efficiency on $\mathrm{CaCO}, \mathrm{BaSO} 4$ as well as is a phosphate-free environment-friendly inhibitor with multi-scale properties. There is a limited corrosion inhibition effect on carbon steel provided by PESA used alone at low concentration, and with the increase of PESA concentration, corrosion inhibition is gradually strengthened. The $\mathrm{pH}$ value has significant effect on corrosion inhibition property of PESA. There is low corrosion inhibition efficiency in acidic condition, as well as better corrosion inhibition efficiency of PESA in alkaline condition. PESA is mainly as the function of anodic corrosion inhibitor. PESA should be a non-phosphorous, biodegradable, environmentally friendly scale and corrosion inhibitor implemented in industrial water treatment.
\end{abstract}

Keywords-polyepoxysuccinic acid; scale and corrosion inhibition; polarization curve; electrochemical impedance spectroscopy

\section{INTRODUCTION}

The formation of mineral scales can cause a series of problems in many processes ranging from desalination to oil production, such as blockage of pipeline, damage of production system, increase of energy consumption, decrease of productivity and unscheduled equipment shutdown ${ }^{[1-10]}$, and eventually result in unwanted increase of operating costs ${ }^{[11-13]}$. The most practical and economical method to combat this problem is the use of chemical scale inhibitors. Recently, the impact of chemicals on the environment is an issue of increasing global importance.

From the middle 1970s to early 1990s, phosphonates had been developed and are extensively used as scale inhibitors. Phosphonates such as HEDP, ATMP, EDTMP, DTPMP, PBTCA, which contain one or more $\mathrm{R}_{3} \mathrm{C}-\mathrm{P}(\mathrm{O})(\mathrm{OH})_{2}$ groups rather than a $\mathrm{R}_{3} \mathrm{C}-\mathrm{O}-\mathrm{P}(\mathrm{O})(\mathrm{OH})_{2}$, possess a number of superior qualities: high chemical stability under extremes of $\mathrm{pH}$ and temperature, the ability to complex metal, the ability to adsorb strongly onto metal coatings, and some dispersancy activity towards suspending matter. However, it is well known that even at moderate conditions of calcium hardness, $\mathrm{pH}$, and temperature, phosphonates can react with calcium ion and precipitate as calcium-phosphonate. Furthermore, phosphonates can also cause eutrophication.

In the past three decades, many water soluble anionic polymers compositions and molecular weights have been developed as scale inhibitors. These polymers are mainly homo-, co-, or ter-polymers having acrylic or maleic as the initial monomer in conjunction with other monomers containing acrylamide, ester, sulfonic acid, phosphonic acid, etc. They possess the excellent ability as a scale inhibitor and metal ion stabilizer. Acrylic acid-based scale inhibitors such as polya- 
crylic acid (PAA), acrylic acid/2-acrylamido-2-methypropane sulfonic acid copolymer (AA/AMPS), acrylic acid/2-acrylamido2-methypropane sulfonic acid/2-hydroxypropyl-acrylate copolymer (AA/AMPS/HPA), although generally of low toxicity, are also unfortunately non-biodegradable.

In the 21 st century, biodegradability, the capability of being broken down into simple, non-toxic materials by the action of microorganisms and fungi, becomes an important mechanism for limiting the build-up of chemicals in the environment. Polyepoxysuccinic acid (PESA) is a novel scale inhibitor first developed by Betzdearbon (U.S.). It is a representative of green scale inhibitors because of its nonnitrogenous, non-phosphorus and biodegradable features. PESA with good scale-inhibiting performances was also synthesized successfully in China ${ }^{[1,2]}$. Versatile scale inhibition performances of PESA were analyzed as well ${ }^{[3-5]}$. According to the advantages of less dosage, high scale inhibition efficiency in the water of high alkalinity and high solid content, as well as the performance of corrosion inhibition, PESA has become a research hotspot now ${ }^{[6]}$. The aims of this paper are to present the corrosion and scale inhibition properties of PESA investigated by using static beaker test, weight-loss method, polarization curves and electrochemical impedance spectroscopy (EIS) in the test water.

\section{EXPERIMENT SECTION}

\section{A. Main Materials}

Polyepoxysuccinic acid (PESA) used in this study was obtained from Wuxi Ecolom Chemical Co. Ltd., China. The PESA was as an aqueous solution (40 wt \%) in the presence of sodium polyepoxysuccinic acid. Molecular weight $\mathrm{M}_{\mathrm{w}}$ of the PESA was approximately 2100, as shown in Figure 1.

Carbon steel specimens used in experiments were composed of the following (wt \%): $0.17 \sim 0.24 \% \mathrm{C}, 0.17 \sim$ $0.37 \% \mathrm{Si}, \quad 0.35 \sim 0.65 \% \mathrm{Mn}, \leq 0.035 \mathrm{P}, \leq 0.035 \mathrm{~S}, \leq 0.025 \mathrm{Ni}$, $\leq 0.025 \mathrm{Cr}, \leq 0.025 \mathrm{Cu}$, and balance Fe.

\section{B. Static Beaker Test for Calcium Carbonate Scale Inhibition Efficiency}

Static beaker calcium carbonate test was conducted by using deionized water and reagent grade chemicals. The static beaker test involved the adding of an amount of the water treatment agent to a solution containing an amount of $\mathrm{Ca}^{2+}$ and an amount of $\mathrm{HCO}_{3}{ }^{-}$at the required $\mathrm{pH}$. The beakers were incubated in a water bath for 18 hour at $80^{\circ} \mathrm{C}$. After cooling, an aliquot was filtered through $0.22 \mu \mathrm{m}$ filter paper, the calcium concentration in the filtrate was measured by using the standard ethylenediamineteraacetic acid (EDTA) titration method. The static scale inhibition efficiency was calculated by

$$
\eta(\%)=\frac{V_{1}-V_{0}}{V_{2}-V_{0}} \times 100
$$

where $V_{1}$ is the amount of consumed EDTA of the sample with the addition of the water treatment agent after incubation, $V_{2}$ is the amount of consumed EDTA of the sample with the addition of the water treatment agent before incubation, $V_{0}$ is the amount of consumed EDTA of the sample without the addition of the water treatment agent after incubation.

\section{Static Beaker Test for Barium Sulfate Scale Inhibition Efficiency}

Static beaker barium sulfate test was conducted by adding of an amount of the water treatment agent to a solution containing an amount of $\mathrm{Ba}^{2+}$ and an amount of $\mathrm{SO}_{4}{ }^{2-}$ at the required $\mathrm{pH}$. The beakers were incubated in a water bath for 18 hour at $80^{\circ} \mathrm{C}$. After cooling, an aliquot was filtered through $0.22 \mu \mathrm{m}$ filter paper; the barium concentration in the filtrate was analyzed by inductively coupled plasma atomic emission spectroscopy (ICP). Barium sulfate inhibition efficiency was calculated by

$$
\eta(\%)=\frac{\left[\mathrm{Ba}^{2+}\right]_{1}-\left[\mathrm{Ba}^{2+}\right]_{0}}{\left[\mathrm{Ba}^{2+}\right]_{2}-\left[\mathrm{Ba}^{2+}\right]_{0}} \times 100
$$

where $\left[\mathrm{Ba}^{2+}\right]_{1}$ is the concentration of barium ion of the sample with the addition of the water treatment agent after incubation, $\left[\mathrm{Ba}^{2+}\right]_{2}$ is the concentration of barium ion of the sample with the addition of the water treatment agent before incubation, $\left[\mathrm{Ba}^{2+}\right]_{0}$ is the concentration of barium ion of the sample without the addition of the water treatment agent after incubation.

\section{Static Beaker Test for Corrosion Inhibition Efficiency}

Static beaker corrosion test was tested by weight loss experiment, which was conducted in a 2 liter beakers equipped with an air/CO2 sparge. The beaker was immersed in a water bath at $45^{\circ} \mathrm{C}$. The carbon steel sheets were polished with different grades of emery paper, degreased with acetone, and rinsed with distilled water. Having been dried and accurately weighed, the carbon steel specimens were immersed in the beaker with the test water in the absence and presence of inhibitors for a period of 72 hours. A typical analysis of the test water is given in Table 1. After test, the carbon steel specimens were taken out, rinsed with water thoroughly, dried and accurately weighted. Each set of experiments was repeated two times to ensure reproducibility. The corrosion inhibition efficiency was calculated by

$$
R(\%)=\frac{W_{0}-W_{\text {I }}}{W_{0}} \times 100
$$

where $\mathrm{R}$ is the corrosion inhibition efficiency, $\mathrm{W} 0$ and $\mathrm{W}$ are the value of the weight loss of carbon steel immersed in test solution without and with inhibitor, respectively. 
TABLE I. ANALYSIS OF THE TEST WATER.

\begin{tabular}{lc}
\hline Parameter & Value \\
\hline $\mathrm{pH}$ & 7.5 \\
Total hardness $\left(\mathrm{mg} \cdot \mathrm{L}^{-1}\right.$, as $\left.\mathrm{CaCO}_{3}\right)$ & 142 \\
$\mathrm{Ca}^{2+}\left(\mathrm{mg} \cdot \mathrm{L}^{-1}\right.$, as $\mathrm{CaCO}$ & \\
Alkalinity $\left(\mathrm{mg} \cdot \mathrm{L}^{-1}\right.$, as $\left.\mathrm{CaCO}_{3}\right)$ & 80 \\
Chloride $\left(\mathrm{mg} \cdot \mathrm{L}^{-1}\right)$ & 62 \\
Sulfate $\left(\mathrm{mg} \cdot \mathrm{L}^{-1}\right)$ & 59 \\
Turbidity $(\mathrm{NTU})$ & 0.22 \\
Total dissolved solids $\left(\mathrm{mg} \cdot \mathrm{L}^{-1}\right)$ & 324 \\
\hline
\end{tabular}

\section{E. Test Method of Tafel Polarization Curve}

The Tafel polarization curve measurements were carried out using a computer controlled potentiostat (Autolab PGSTAT30) in a three electrode cell assembly at a scan rate of $1 \mathrm{mV} / \mathrm{s}$. A platinum electrode and a saturated calomel electrode (SCE) were used as auxiliary and reference electrode respectively. The work electrode (WE) was a carbon steel specimen of area $1 \mathrm{~cm} 2$. All the experiments were carried out at $30 \pm 2^{\circ} \mathrm{C}$ with the test water (shown in table 1) as an electrolyte under static and naturally aerated condition. The Tafel polarization curve studies were conducted in the test water containing various concentrations of inhibitor. The experiments were repeated to ensure reproducibility. The inhibition efficiency of the inhibitor for the carbon steel corrosion was calculated by

$$
R(\%)=\frac{W_{0}-W_{\mathrm{I}}}{W_{0}} \times 100
$$

\section{F. Electrochemical Impedance Spectroscopy (EIS)}

The same instrument of the Tafel polarization curve measurements was used for electrochemical impedance measurement (Autolab PGSTAT30) at $30 \pm 2^{\circ} \mathrm{C}$. Electrochemical impedance measurement was carried out in the region of 0.01 $\mathrm{Hz}$ to $100 \mathrm{KHz}$ with the perturbation amplitude of $5 \mathrm{mV}$.

\section{RESULTS AND DISCUSSION}

\section{A. Calcium Carbonate Scale Inhibition Performance}

In accordance with the experiment method 2.2, the additional experimental conditions are as follows: the mass concentration of $\mathrm{Ca}^{2+}$ and $\mathrm{HCO}_{3}{ }^{-}$are $500 \mathrm{mg} \cdot \mathrm{L}^{-1}$ and $750 \mathrm{mg} \cdot \mathrm{L}^{-}$ ${ }^{1}$ respectively, $\mathrm{pH}$ value of the solution is 9.0 . The comparison of static scale inhibition efficiency between PESA and other typical phosphonates is shown in Figure 1. It can be seen that although the $\mathrm{CaCO}_{3}$ scale inhibition efficiency of PESA is a little less than PBTCA, but more than polycarboxylic acid inhibitors PAA and PMAAA, sulfonate inhibitors AA/AMPS, and polyphosphoric acid inhibitor SHMP. Therefore, PESA has good scale inhibition efficiency on $\mathrm{CaCO}_{3}$.

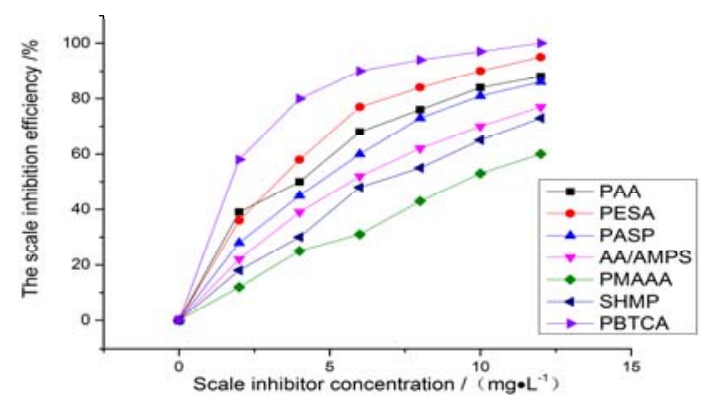

FIGURE I. INFLUENCE OF SCALE INHIBITOR CONCENTRATION

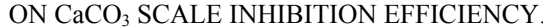

\section{B. Barium Sulfate Scale Inhibition Performance}

According to the experiment method 2.3, the additional experimental conditions are as follows: the mass concentration of $\mathrm{Ba}^{2+}$ and $\mathrm{SO}_{4}{ }^{2-}$ are $20 \mathrm{mg} \cdot \mathrm{L}^{-1}$ and $100 \mathrm{mg} \cdot \mathrm{L}^{-1}$ respectively, $\mathrm{pH}$ value of the solution is 7.0. As demonstrated, PESA and SHMP have good scale inhibition effect on $\mathrm{BaSO}_{4}$, while the PAA, PMAAA, AA/HPA/AMPS and PBTCA still have no $\mathrm{BaSO}_{4}$ scale inhibition effect even at the concentration of $15 \mathrm{mg} \cdot \mathrm{L}^{-1}$. The impacts of PESA, SHMP and PASP concentration on $\mathrm{BaSO}_{4}$ scale inhibition efficiency are shown in Figure 2. As demonstrated in Figure 2, the $\mathrm{BaSO}_{4}$ scale inhibition efficiency of PESA is superior to the traditional Ba$\mathrm{SO}_{4}$ scale inhibitor SHMP; as a result, PESA has a very strong scale inhibition effect on $\mathrm{BaSO}_{4}$.

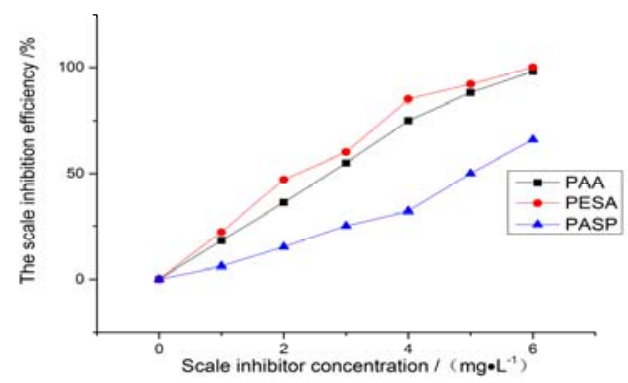

FIGURE II. INFLUENCE OF SCALE INHIBITOR CONCENTRATION ON BaSO4 SCALE INHIBITION EFFICIENCY.

\section{Static Beaker Test for Corrosion Inhibition}

The static corrosion inhibition efficiency of PESA to carbon steel at different concentration is shown in Table 2 and Figure 3, which was tested by weight loss experiment.

Table 2 and Figure 3 illustrate that, under the condition of this water quality, the corrosion inhibition effects of PESA used alone to carbon steel at low concentrations is weak, and with the increase of PESA concentration, corrosion inhibition is gradually strengthened. Therefore, to achieve a better inhibition affect, the required quality concentration of PESA should be higher. 
TABLE II. THE WEIGHT LOSS EXPERIMENT RESULTS AT DIFFERENT PESA CONCENTRATION.

\begin{tabular}{|c|c|c|}
\hline $\operatorname{PESA}\left(\mathrm{mg} \cdot \mathrm{L}^{-1}\right)$ & Corrosion velocity $\left(\mathrm{mm} \cdot \mathrm{a}^{-1}\right)$ & $\begin{array}{l}\text { Corrosion inhibition } \\
\text { efficiency }(\%)\end{array}$ \\
\hline 0 & 1.3855 & - \\
\hline 50 & 1.3524 & 2.39 \\
\hline 100 & 1.2654 & 8.67 \\
\hline 150 & 0.4799 & 65.36 \\
\hline 200 & 0.3482 & 74.87 \\
\hline 800 & 0.2454 & 82.29 \\
\hline
\end{tabular}

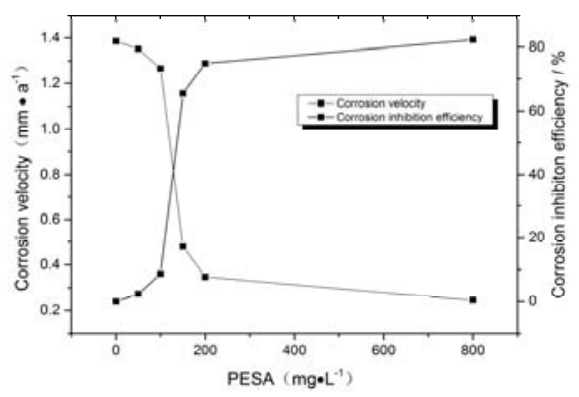

FIGURE III. PESA CONCENTRATION_CORROSION VELOCITYCORROSION INHIBITION EFFICIENCY.

Table 3 illustrates the effect on the static corrosion inhibition efficiency of PESA to carbon steel at different $\mathrm{pH}$ values according to the weight loss experiment. The $\mathrm{pH}$ values of the test solution were adjusted to 2, 4, 9 respectively, and then dosing $200 \mathrm{mg} \cdot \mathrm{L}^{-1}$ of PESA to carry out weight loss experiment.

As shown in Table 2, it demonstrates that $\mathrm{pH}$ value has significant effect on corrosion inhibition property of PESA. There is low corrosion inhibition efficiency in acidic condition; as the $\mathrm{pH}$ value increases, the corrosion velocity of carbon steel obviously decreases as well as corrosion inhibition efficiency increases, namely corrosion inhibition enhances. Moreover, in alkaline condition, the corrosion inhibition efficiency of PESA is better and can reach about $80 \%$. It is assumed that, due to the alkaline environment, PESA may dissociate, which contributes to its adsorption on the carbon steel surface.

TABLE III. THE WEIGHT LOSS EXPERIMENT RESULTS OF PESA AT DIFFERENT PH VALUES OF TEST SOLUTION.

\begin{tabular}{|l|c|c|c|}
\hline $\mathrm{pH}$ & $\operatorname{PESA}\left(\mathrm{mg} \cdot \mathrm{L}^{-1}\right)$ & $\begin{array}{l}\text { Corrosion veloci- } \\
\text { ty }\left(\mathrm{mm} \cdot \mathrm{a}^{-1}\right)\end{array}$ & $\begin{array}{l}\text { Corrosion inhibition } \\
\text { efficiency }(\%)\end{array}$ \\
\hline 2 & 0 & 4.5357 & - \\
\hline 2 & 200 & 3.9118 & 13.76 \\
\hline 4 & 0 & 1.6462 & - \\
\hline 4 & 200 & 0.6587 & 60.00 \\
\hline 12 & 0 & 0.1378 & - \\
\hline 12 & 200 & 0.0227 & 83.53 \\
\hline
\end{tabular}

\section{The Tafel Polarization Curve Measurement}

The polarization curve experiments of carbon steel at different $\mathrm{pH}$ values of test solution $(\mathrm{pH}=2,4,9)$ were carried out and the corresponding results are given in Figure 4-6. As they illustrated, it is found that there are all greater impact on the anodic process of electrodes by adding PESA at different $\mathrm{pH}$ values of test solution; this effect amplified as the $\mathrm{pH}$ value increases, and the self-corrosion potential turns to the positive shift. In other words, PESA belongs to anodic corrosion inhibitor.

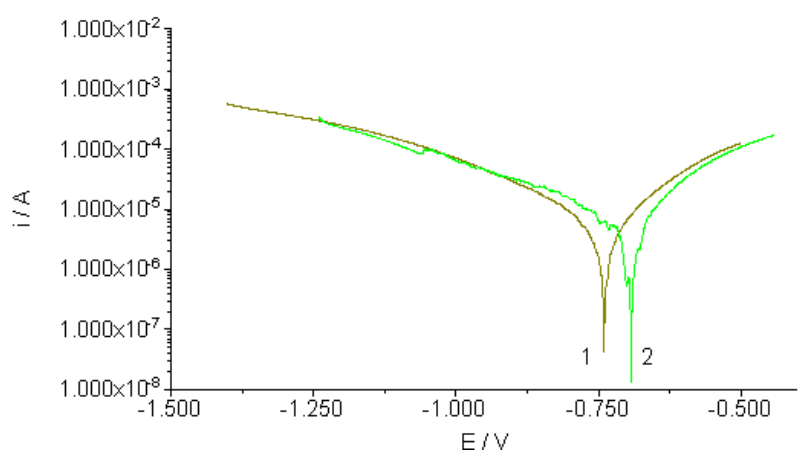

FIGURE IV. THE POLARIZATION CURVE OF PESA AT PH=2. (1PESA, 2-BLANK)

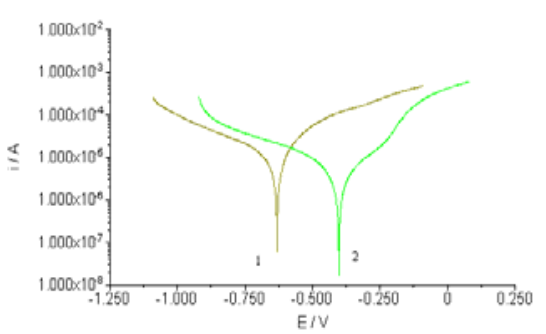

FIGURE V. THE POLARIZATION CURVE OF PESA AT PH $=4$ (1-PESA, 2-BLANK).

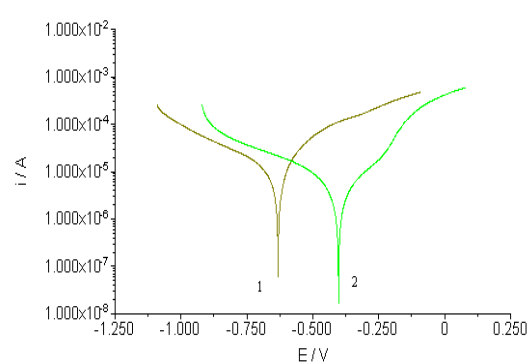

FIGURE VI. THE POLARIZATION CURVE OF PESA AT PH $=9(1-$ PESA; 2-BLANK.)

Figure 7 shows the results of polarization curve tests to carbon steel at different concentrations of PESA $\left(50 \mathrm{mg} \cdot \mathrm{L}^{-1}\right.$, $100 \mathrm{mg} \cdot \mathrm{L}^{-1}, 150 \mathrm{mg} \cdot \mathrm{L}^{-1}, 200 \mathrm{mg} \cdot \mathrm{L}^{-1}$ and $800 \mathrm{mg} \cdot \mathrm{L}^{-1}$, respectively). The parameters, such as polarization resistance (Rp), self-corrosion potential (Ecorr), anodic Tafel Slope, cathodic Tafel slope, etc., as well as corrosion velocity, can be obtained by using the software of PGATAT30 electrochemical 
workstation to carry out the Tafel extrapolation to the active part of the polarization curves in Figure $4^{[7,8]}$, and then corrosion inhibition efficiency can be calculated according to the corrosion velocity of the blank specimen. The data is shown in Table 4.

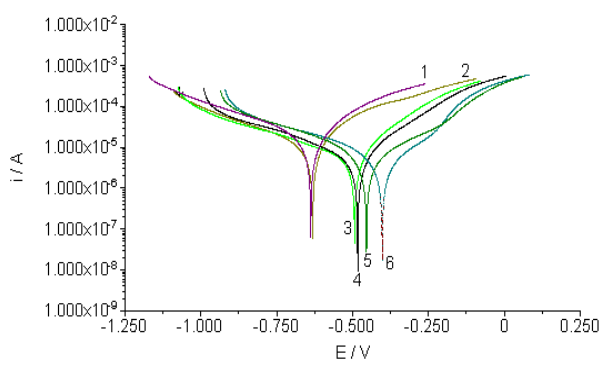

FIGURE VII. THE POLARIZATION CURVES OF PESA AT DIFFERENT CONCENTRATIONS.

(1-800mg $\cdot \mathrm{L}^{-1} ; 2-\mathrm{Blank} ; 3-50 \mathrm{mg} \cdot \mathrm{L}^{-1} ; 4-100 \mathrm{mg} \cdot \mathrm{L}^{-1} ; 5-200 \mathrm{mg} \cdot \mathrm{L}^{-1} ; 6-150 \mathrm{mg} \cdot \mathrm{L}^{-}$ $\left.{ }^{1}\right)$

As it is observed in Table 4, the corrosion inhibition efficiency is better by adding more PESA in the neutral solution medium. When PESA is used alone, aiming to achieve better corrosion inhibition efficiency, the concentration of PESA should reach $200 \mathrm{mg} \cdot \mathrm{L}^{-1}$ or more. The OCP of PESA at different concentrations increase obviously compared to the blank, which demonstrates that PESA is mainly as the function of anodic inhibitor $[9,10]$. The reason contributes to this is that PESA adsorbs on the carbon steel surface and reacts with $\mathrm{Fe}^{3+}$, but also forms the membrane which hampers the proliferation of $\mathrm{Fe}^{2+}$ in the anodic area, so that it comes anodic polarization and anodic potential rise, and eventually leading Ecorr to be higher.

From Figure 7, it is shown that there is no significant inhibition efficiency for the anode reaction of carbon steel by adding $100 \mathrm{mg} \cdot \mathrm{L}^{-1}$ of PESA, indicating that the PESA concentration is not high enough, the formed membrane has poor density and may even only covers part of the surface of carbon steel. The formed membrane by PESA, which is incomplete, makes effect on its inhibition efficiency, and thus the anode reaction cannot be effectively curbed.

Compared with the blank, the anodic Tafel Slope rises markedly with the PESA concentration increases, which illustrating that the presence of PESA controls the anode in the reaction, so as to inhibit the anodic reaction of corrosion process. Accompanying with the concentration of PESA reaching above $200 \mathrm{mg} \bullet \mathrm{L}^{-1}$, the corrosion potential Ecorr decreases as well as the Tafel Slop of cathodic polarization curves rises, in accordance with which it implies that the process of cathodic reaction begins to be inhibited as the concentration of PESA increases. PESA can chelate $\mathrm{Ca}^{2+}, \mathrm{Mg}^{2+}$ and other ions in the test solution and then disperse in it; with the increased concentration of PESA, part of the chelate deposit in the cathode region and thus the cathodic process is suppressed [11].

TABLE IV. THE POLARIZATION PARAMETERS OF DIFFERENT CONCENTRATIONS OF PESA AT $30^{\circ} \mathrm{C}$.

\begin{tabular}{|c|c|c|c|c|c|c|c|}
\hline $\begin{array}{c}\text { Mass } \\
\text { concentration } \\
\left(\mathrm{mg} \cdot \mathrm{L}^{-1}\right)^{-1}\end{array}$ & $\begin{array}{c}\mathrm{OCP} \\
4 \\
(\mathrm{mV})\end{array}$ & $\begin{array}{c}E c o r r \\
+ \\
(\mathrm{mV})\end{array}$ & $\begin{array}{c}\mathrm{Rp} \\
4 \\
\times 10^{3} \mathrm{oh} \\
\mathrm{m}\end{array}$ & $\begin{array}{c}\mathrm{Ba} \\
+\mathrm{m} \cdot \mathrm{dec} \\
1)\end{array}$ & $\begin{array}{c}B \alpha^{-1} \\
\left(m \cdot \operatorname{dec}^{-1}\right)\end{array}$ & $\begin{array}{l}\text { Corrosion- } \\
\text { velocity } \\
\left(\mathrm{mm} \cdot \mathrm{a}^{-1}\right)\end{array}$ & $\begin{array}{c}\text { Corrosion mhibi- } \\
\text { tion efficiency } \\
(\%)\end{array}$ \\
\hline 04 & -4904 & -635 & 4.004 & 170 & 368 & 0.1126 & דיה \\
\hline 50 & -475 & -498 & 6.91 & 128 & 395 & 0.0702 & 37.66 \\
\hline 100 & ק & -480 & 7.81 & 204 & 406 & 0.0681 & 39.52 \\
\hline 150 & -320 & -390 & 1.06 & 206 & 492 & 0.0439 & 61.01 \\
\hline 2004 & -335 & -450 & 8.904 & 271 & 435 & 0.0312 & 72.29 \\
\hline $8000^{3}$ & -571 & -6304 & $3.01 \mathrm{P}$ & 212 & 397 & 0.0209 & 81.44 \\
\hline
\end{tabular}

As the concentration of PESA further up to $800 \mathrm{mg} \cdot \mathrm{L}^{-1}$, the cathode Tafel Slop of PESA polarization curve increases, it is inferred there may be a reaction between $\mathrm{Mg}^{2+}$ and $\mathrm{OH}^{-}$ generated in the cathode reaction, and the product $\mathrm{Mg}(\mathrm{OH})_{2}$ deposits in the cathode region as to prevent the spread of oxygen and thus inhibit the cathode reaction [12-16].

\section{E. Electrochemical Impedance Measurement}

The EIS Nyquist plots of carbon steel electrode after the tests of dosing different concentrations of PESA in the solution have been shown in Figure 8. Since the impedance is plural, the horizontal axis is for the real part while the vertical axis is for the imaginary part. As can be seen from Figure 8, impedance spectra suffers different degrees of large semicircular features; under the condition that the dosing concentration of PE-
$\mathrm{SA}$ is less than $100 \mathrm{mg} \cdot \mathrm{L}^{-1}$, the increasing range of $\mathrm{Rp}$ value (charge transfer resistance) with the rising of the concentration. It demonstrates that corrosion inhibition efficiency is not very good in terms of the low dosing concentration of PESA; when the concentration to be more than $100 \mathrm{mg} \cdot \mathrm{L}^{-1}$, Rp value increases by a large margin. The greater $R p$ value indicates that the adsorbed membrane on the surface of carbon steel is thicker by the action of corrosion inhibitor, and it also comes out greater absorption area as well as the better inhibition efficiency, due to which the increase of the Rp value illuminates that PESA has significant corrosion inhibition effect to carbon steel.

The high-frequency capacitance arc appearing in the highfrequency zone of the impedance spectroscopy shows that there is a more complete adsorbed membrane forming on the surface of electrode, and the metallic corrosion reaction is in- 
hibited, moreover, the charge transfer reaction plays a leading role in metal corrosion process. The chord length from semicircle to the real axis ( $Z^{\prime}$ axis) corresponds to the charge transfer resistance Rp. In terms of the corrosion inhibitor system, $\mathrm{Rp}$ reflects the resistance for the process of metal ionization by the covering layer of corrosion inhibitor, or reflects the rate of corrosion reaction. The greater $\mathrm{Rp}$ value is, indicating the greater resistance for the process of metal ionization while the smaller corrosion rate of metals.

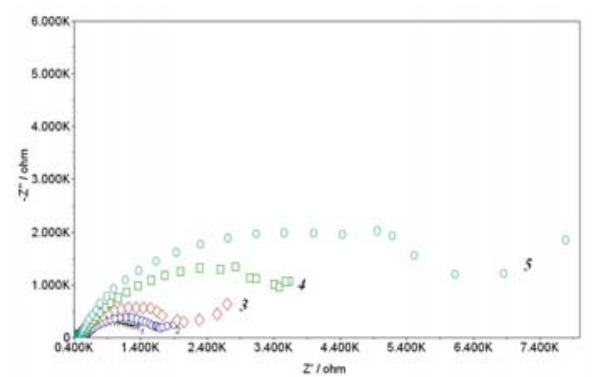

FIGURE VIII. THE EIS NYQUIST PLOTS OF CARBON STEEL ELECTRODE IN THE SOLUTIONS ADDED DIFFERENT CONCENTRATIONS OF PESA.

(1-Blank; 2-50 mg $\cdot \mathrm{L}^{-1} ; 3-100 \mathrm{mg} \cdot \mathrm{L}^{-1} ; 4-150 \mathrm{mg} \cdot \mathrm{L}^{-1} ; 5-200 \mathrm{mg} \cdot \mathrm{L}^{-1}$ )

Table 5 shows the corrosion inhibition efficiency at different concentrations of PESA calculated by

$$
\eta=\left(1-\mathrm{Rp}_{0} / \mathrm{Rp}\right) \times 100 \%
$$

where $\mathrm{Rp}$ and $\mathrm{Rp}_{0}$ are the charge transfer resistance in test solution with and without corrosion inhibitor, respectively. The greater the concentration of PESA, the stronger the corrosion inhibition effect within the scope of the experiment, which is indicated in Figure 9.

TABLE V. AC IMPEDANCE AT DIFFERENT CONCENTRATIONS OF PESA.

\begin{tabular}{|c|c|c|}
\hline PESA $\left(\mathrm{mg} \cdot \mathrm{L}^{-1}\right)$ & Rp $(\mathrm{ohm})$ & $\eta(100 \%)$ \\
\hline 0 & $4.99971 \times 10^{2}$ & - \\
\hline 50 & $1.19138 \times 10^{3}$ & 58.03 \\
\hline 100 & $1.75014 \times 10^{3}$ & 71.43 \\
\hline 150 & $3.86054 \times 10^{3}$ & 87.05 \\
\hline 200 & $6.62408 \times 10^{3}$ & 92.45 \\
\hline
\end{tabular}

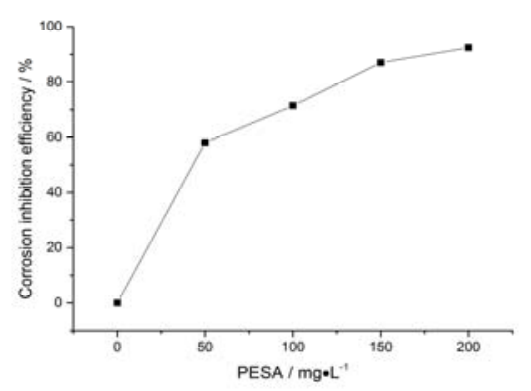

FIGURE IX. PESA CONCENTRATION-CORROSION INHIBITION EFFICIENCY.

\section{CONCLUSION}

Under the experimental conditions in this paper, comparing with the scale inhibitors, such as PBTCA, PAA, PMAAA and AA/AMPS, PESA and SHMP has scale inhibition effect on $\mathrm{CaCO}_{3}\left(12 \mathrm{mg} \cdot \mathrm{L}^{-1}\right.$ of the scale inhibitor's concentration) and $\mathrm{BaSO}_{4}\left(6 \mathrm{mg} \cdot \mathrm{L}^{-1}\right.$ of the scale inhibitor's concentration), furthermore, the scale inhibition efficiency on $\mathrm{CaCO}_{3}, \mathrm{BaSO}_{4}$ of PESA is much better than SHMP. Meanwhile, SHMP is easy to decompose into the precipitation of calcium phosphate, reducing its scale inhibition efficiency, but also has high phosphorus content, while the PESA is a phosphate-free environment-friendly inhibitor with versatile scale inhibition properties, and thus it has a very broad application prospects.

There is limited corrosion inhibition effect on carbon steel provided by PESA used alone at low concentration $(<120 \mathrm{mg}$ - $\mathrm{L}^{-1}$ ), and with the increase of PESA concentration, corrosion inhibition is gradually strengthened.

The $\mathrm{pH}$ value has significant effect on corrosion inhibition property of PESA. And PESA has corrosion inhibition effects to carbon steel by $120 \mathrm{mg} \cdot \mathrm{L}^{-1}$ of the concentration to some degree. However, there is low corrosion inhibition efficiency in acidic condition; as the $\mathrm{pH}$ value increases, the corrosion velocity of carbon steel obviously decreases as well as corrosion inhibition efficiency increases, namely corrosion inhibition enhances. Moreover, in alkaline condition, the corrosion inhibition efficiency of PESA is better and can reach about $80 \%$. PESA is mainly as the function of anodic corrosion inhibitor.

PESA curbs metallic corrosion process by forming the absorbed membrane on the surface of carbon steels, as well as the charge transfer reaction plays a leading role in metal corrosion process.

PESA should be a non-phosphorous, biodegradable, environmentally friendly scale and corrosion inhibitor implemented in industrial water treatment.

\section{REFERENCE}

[1] SUN Yonghong, XIANG Wenhua, WANG Ying, Study on polyepoxysuccinic acid reverse osmosis scale inhibitor.Journal of Environmental Sciences, Volume 21, Supplement 1, 2009, Pages S73-S75

[2] Xiong R C, Zhou Q, Wei G, 2003. Corrosion inhibition and synergistic effect of green scale inhibitor polyepoxysuccinic acid. Journal of Chemical Industry and Engineering, 54(9): 1323-1325.

[3] Lei W, Wang F Y, Xia M Z, Wang F H, 2006. Synthesis and its scale inhibition effect of green scale inhibitor polyepoxysuccinic acid. Journal of Chemical Industry and Engineering, 57(9): 2207-2213.

[4] Zhang R B, Li F T, 2002. Versatile scale inhibition of polyepoxysuccinic acid. Industrial Water Treatment, 22(9): 21-24.

[5] Zhou W S, Du Q Y, Yu R X, Zhang L, Wei W Y, 2006. Evaluation of the scale inhibition effect of PESA on RO system. Industrial Water Treatment, 26(10): 58-60.

[6] Carter, C. G., Fan, L. G., Fan, J. C., Kreh, R. P. and Jovancicevic, V. 1994. Method of inhibiting corrosion of metals using polytartaric acids. EP Patent No. 0609590.

[7] NIE Lijun, TAN Chengyu, 2005. Corrosion behavior of A3 steel in sulfuric acid solutions. Corrosion \& Protection, 26(10):439-432.

[8] S. Keritit, B. Hammouti. Corrosion inhibition of iron in $1 \mathrm{M} \mathrm{HCl}$ by 1phenyl-5-mercapto-1, 2, 3, 4-tetrazole. Applied Surface Science, 1996,(93):59-66. 
[9] K.F. Khaled, N. Hackerman, Mater. Chem. Phys, 82(2003)949.

[10] K.F. Khaled, N. Hackerman, Electrochimica Acta, 82(2003)949.

[11] Yu Hui, Wu Jianhua, Wang Hongren, et al, 2002. Studies on The Inhibition of YKI-05 Corrosion Inhibitor to 907A Steel in Different Immersed Environments. Electrochemistry, 8(4):439-444.

[12] TAN Weigang, LU Zhu, LI Yan, 2001. A study of tungstate-based water treatment agents without phosphate for inhibiting corrosion and scaling. Corrosion \& Protection, 22(6):237-239.

[13] Li Yan, Lu Zhu, 2000. Application of surface analysis technology in study on corrosion inhibition mechanism of tungstate. Corrosion \& Protection, 21(10):447-450.

[14] WANG Chao, CHEN Xinping, LIANG Limin. Green Chemistry and Corrosion and Scale Inhibitors. Chemistry and Adhesion, 4 (2001):171173.

[15] ZHANG Jianqiang, YAN Lianhe, WANG Ying,2002. Research Advancement of Green Revolution in High Polymeric Chemicals for Water Treatment. Jiangsu Chemical Industry, 30(4):27-30.

[16] Harvey J. Flitt, D. Paul Schweinsberg. Evaluation of corrosion rate from polarisation curves not exhibiting a Tafel region. Corrosion Science 47 (2005) 3034-3052. 